\title{
EVALUATION OF HISTOPATHOLOGICAL RISK FACTORS IN ENUCLEATED RETINOBLASTOMA EYES
}

\author{
Nibedita Acharya ${ }^{1}$, Usha Vasu ${ }^{2}$
}

${ }_{1}^{1}$ Associate Professor, Department of Ophthalmology, BGS Global Institute of Medical Sciences, Bangalore. 2Professor, Department of Ophthalmology, St. Johns Medical College and Hospital, Bangalore.

\section{BACKGROUND}

ABSTRACT

Recent advance in radiotherapy and chemotherapy has revolutionised the treatment and survival of retinoblastoma (RB) patients. Despite this success, presence of clinical, genetic and histopathological risk factors can lead to systemic metastasis of the disease. Documented histopathological (HP) risk factors for metastasis in retinoblastoma include choroidal invasion, trans-scleral migration and intra-neural invasion. The need for preventive chemotherapy in a patient is decided on evaluating these HP features in an enucleated eye.

The aim of this study is to look for presence of HP risk factors in enucleated retinoblastoma eyes.

\section{MATERIALS AND METHODS}

This descriptive study was done at St. John's Medical College Hospital (SJMCH) and Kidwai Institute of Oncology (KMIO), Bangalore from May 2005 to January 2015. It is partly retrospective and largely prospective study. Thirty nine eyes of 39 Retinoblastoma patients were included in the study. Their age and sex were noted. Ocular examination findings were documented. Detailed histopathological examination of enucleated eyes and the slides were done to look for presence of HP risk factors like choroidal invasion, scleral extension and optic nerve involvement, etc. Patients having histopathological risk factors were started on adjuvant chemotherapy.

\section{RESULTS}

Thirty nine enucleated eyes of 39 patients were included in the study during the study period. The mean age of these 39 patie nts was 3 years. Tumour was unilateral in 21 (53.8\%) cases and bilateral in 18 (46.2\%) cases. Sixteen eyes had Grade-IV and 23 eyes had Grade-V tumour by Reese-Ellsworth staging. On histopathological examination, nine eyes out of 39 (23\%) showed presence of HP risk factors like choroidal invasion -6 cases (15.3\%), scleral infiltration - 2 cases (5\%), post laminar optic nerve invasion - 6 cases $(15.3 \%)$ and optic nerve sheath invasion -3 cases $(7.6 \%)$. Four children $(10.2 \%)$ had systemic metastasis in the series.

\section{CONCLUSION}

Presence of histopathological risk factors in enucleated retinoblastoma eyes have significant therapeutic and prognostic value. All enucleated eyes should be carefully checked for presence of any of these factors and if these features are there, then subsequent antimetastatic treatment should be started for the patients.

\section{KEYWORDS}

Retinoblastoma, Histopathological Risk Factors, Choroidal Invasion, Optic Nerve Invasion.

HOW TO CITE THIS ARTICLE: Acharya N, Vasu U. Evaluation of histopathological risk factors in enucleated retinoblastoma eyes. J. Evolution Med. Dent. Sci. 2018;7(01):9-11, DOI: 10.14260/jemds/2018/3

\section{BACKGROUND}

Retinoblastoma is the most common intraocular malignancy seen in children. Over the past century, the survival rate of retinoblastoma has improved from 5\% to 95\%. Early diagnosis and improved treatment methods, are mostly responsible for the better survival.1,2 Even then, some patients still suffer extraocular metastasis that may lead to death. Early recognition of risk factors for metastasis may offer the potential to improve survival. Several high-risk factors documented to be associated with extraocular recurrence have been identified upon Histopathological (HP) examination of enucleated eyes, which include invasion of post-laminar optic nerve, trans-scleral migration, choroidal invasion and anterior chamber seeding. $3,4,5,6$

'Financial or Other Competing Interest': None.

Submission 16-11-2017, Peer Review 14-12-2017,

Acceptance 20-12-2017, Published 01-01-2018.

Corresponding Author:

Dr. Nibedita Acharya,

\# 105, B-Block, Esteem Enclave,

Arekere Gate,

Bannerghatta Road, Bangalore-560076.

E-mail:dr.nibedita76@gmail.com

DOI: $10.14260 /$ jemds $/ 2018 / 3$

\section{(c) (i) $($ )}

The need for preventive chemotherapy in a patient is decided after evaluating these HP features in an enucleated eye. 7,8

\section{Objective}

When two of our retinoblastoma patients, whose HP Reports only said: "cut end of the optic nerve not involved", developed orbital and systemic metastasis; we undertook this study to do detailed HP examination of all enucleated retinoblastoma eyes and the histopathological slides. The objective of this study is to look for presence of any Histopathological risk factors like, iris invasion, choroidal invasion, trans-scleral migration and optic nerve involvement etc. in enucleated retinoblastoma eyes.

\section{MATERIALS AND METHODS}

This study was conducted at St. John's Medical College Hospital (SJMCH) and Kidwai Institute of Oncology (KMIO), Bangalore from May 2005 to January 2015. This is a descriptive study which is partly retrospective and largely prospective. Thirty-nine eyes of 39 Retinoblastoma patients were included in the study. Along with the age and sex of the patients, ocular features like laterality of tumour, intra-ocular 
pressure and anterior segment involvement by tumour cells, were noted down. Tumour size and type of tumour were also recorded. Retinoblastoma eyes were classified according to Reese-Ellsworth staging.

Routine histopathological sections were stained with haematoxylin-eosin stain. The enucleated globe (in those cases where it was available) and the histopathological slide in all patients were reviewed by a pathologist and paediatric oncologist at SJMCH and KMIO, for presence of histopathological risk factors like choroidal invasion, iris infiltration, scleral extension, optic nerve invasion posterior to lamina cribrosa and involvement of cut end of optic nerve by tumour cells. The other demographic and clinical data of these patients were then correlated with the revised HP reports.

\section{RESULTS}

Thirty-nine enucleated eyes of 39 patients were included in the study during the study period. Of these, 22 eyes were enucleated at SJMCH and 17 at other hospitals. Only 30 patients had globe with slides for re-examination. The rest nine patients had only slides available. The initial HP reports of some of these children were incomplete reports (Those reports did not mention any other HP risk factors apart from "cut end of optic nerve involvement"). The mean age of these 39 patients at the time of enucleation was 3 years (range: 2 months to 9 years). There were 25 male (64\%) and 14 female (36\%) patients. Tumour was unilateral in 21 (53.8\%) cases and bilateral in $18(46.2 \%)$ cases. The intra-ocular pressure (IOP) was more than $20 \mathrm{mmHg}$ in seven cases, normal in 30 cases and low in two cases. Anterior segment examination was normal in 36 patients while three had hyphaema at the time of presentation. The Reese-Ellsworth staging of these enucleated eyes were: Grade I- no cases; Grade II- no cases; Grade III- no cases; Grade IV - 16 cases (41\%); Grade V- 23 cases (59\%). The largest tumour dimension was less than 15 $\mathrm{mm}$ in 20 patients and more than $15 \mathrm{~mm}$ in 19 patients. The tumour was endophytic in 29 patients, exophytic in nine cases and diffuse infiltrating in one case. There was presence of vitreous seeding on examination in seven cases.

After re-examination, the HP Report of these 39 enucleated eyes, showed the following findings:

- Tumour invasion posterior to lamina cribrosa - One patient

- Tumour invasion to lamina cribrosa along with optic nerve sheath and choroidal invasion - Three patients

- Scleral invasion with choroidal invasion - Two patients

- Choroidal invasion with iris infiltration -- One patient

- Infiltration posterior to lamina cribrosa, but not involving the cut end of Optic Nerve (Both also had less than $8 \mathrm{~mm}$ Optic Nerve length) -- Two patients

- $\quad$ No HP risk factors found -30 patients

Out of Thirty-nine eyes, nine eyes (23\%) showed features of extraretinal tumour extension. Choroidal invasion was seen in six cases $(15.3 \%)$, scleral infiltration was present in two cases (5\%), post laminar optic nerve invasion in six cases $(15.3 \%)$ and optic nerve sheath invasion seen in three cases (7.6\%) (Table - 1 shows the above findings).

\begin{tabular}{|c|c|}
\hline Histopathological Finding & No. of Cases \\
\hline Choroidal invasion by tumour cells & 6 \\
\hline Optic nerve involvement by tumour cells & 6 \\
\hline Scleral invasion by tumour cells & 2 \\
\hline $\begin{array}{l}\text { Optic nerve sheath invasion by tumour } \\
\text { cells }\end{array}$ & 3 \\
\hline Iris infiltration by tumour cells & 1 \\
\hline
\end{tabular}

The clinical profile of these nine patients were analysed retrospectively and, it did show a more advanced stage of tumour with extraretinal involvement in those patients. Table- 2 summarises the clinical features in these nine patients.

\begin{tabular}{|c|c|c|}
\hline Sl. No. & HP Risk Factors & Clinical Risk Factors \\
\hline 1 & $\begin{array}{l}\text { Choroidal invasion with } \\
\text { optic nerve and nerve } \\
\text { sheath infiltration }\end{array}$ & $\begin{array}{c}\text { Advanced retinoblastoma } \\
\text { Stage-V; Exophytic } \\
\text { tumour }>15 \mathrm{~mm}\end{array}$ \\
\hline 2 & $\begin{array}{l}\text { Choroidal invasion with } \\
\text { Optic Nerve and nerve } \\
\text { sheath infiltration }\end{array}$ & $\begin{array}{c}\text { Advanced retinoblastoma } \\
\text { Stage V; Exophytic } \\
\text { tumour, raised IOP }\end{array}$ \\
\hline 3 & $\begin{array}{c}\text { Choroidal invasion with } \\
\text { Optic Nerve and nerve } \\
\text { sheath infiltration }\end{array}$ & $\begin{array}{c}\text { Retinoblastoma Stage-V; } \\
\text { Exophytic tumour > } 15 \\
\text { mm, raised IOP } \\
\end{array}$ \\
\hline 4 & $\begin{array}{l}\text { Choroidal invasion with } \\
\text { scleral invasion }\end{array}$ & $\begin{array}{c}\text { Stage V tumour; tumour } \\
\text { size }>15 \text { mm, Diffuse } \\
\text { infiltrating type with low } \\
\text { IOP }\end{array}$ \\
\hline 5 & $\begin{array}{r}\text { Choroid } \\
\text { scle }\end{array}$ & $\begin{array}{l}\text { Stage V tumour; tumour } \\
\text { size }>15 \mathrm{~mm} \text {, low IOP }\end{array}$ \\
\hline 6 & $\begin{array}{l}\text { Choroidal invasion with } \\
\text { iris infiltration }\end{array}$ & $\begin{array}{c}\text { Retinoblastoma Stage-V; } \\
\text { Layered hyphaema, } \\
\text { Endophytic tumour with } \\
\text { high IOP }\end{array}$ \\
\hline 7 & $\begin{array}{l}\text { Optic nerve infiltration } \\
\text { posterior to lamina } \\
\text { cribrosa }\end{array}$ & $\begin{array}{l}\text { Endophytic tumour }>15 \\
\text { mm; vitreous seeding + }\end{array}$ \\
\hline 8 & $\begin{array}{c}\text { Optic Nerve infiltration } \\
\text { posterior to lamina } \\
\text { cribrosa } \\
\end{array}$ & $\begin{array}{c}\text { Stage-V endophytic } \\
\text { tumour with vitreous } \\
\text { seeding }\end{array}$ \\
\hline 9 & $\begin{array}{l}\text { Optic Nerve infiltration } \\
\text { posterior to lamina } \\
\text { cribrosa }\end{array}$ & $\begin{array}{l}\text { Stage } V \text { tumour; tumour } \\
\text { size }>15 \mathrm{~mm}\end{array}$ \\
\hline \multicolumn{3}{|c|}{$\begin{array}{c}\text { Table 2. HP Risk Factors and its Correlation } \\
\text { with Clinical Features }\end{array}$} \\
\hline
\end{tabular}

All the Nine patients showing HP risk factors on reexamination were started on antimetastatic chemotherapy (six cycles of adjuvant chemotherapy with vincristine, carboplatin and etoposide) and orbital external beam radiotherapy.

Two children after the first cycle of chemotherapy were lost to follow-up, but presented 4 months and 6 months later with orbital and systemic metastasis. The second child died in spite of treatment. Rest of the children are doing well with no recurrence to date.

\section{DISCUSSION}

Retinoblastoma metastasises through haematogenous dissemination, lymphatic spread, direct infiltration along the optic nerve and dispersion through the cerebrospinal fluid, after cells in the optic nerve invade the leptomeninges. ${ }^{9}$ Early recognition of risk factors for metastasis and timely intervention may improve the survival of retinoblastoma 
patients. Risk factors for metastasis include age of patient at diagnosis, laterality of tumour, genetics, high intra-ocular pressure, histopathology and extraocular extension of tumour. ${ }^{5}$ Identifying these risk factors early is crucial to start antimetastatic chemotherapy. On histopathological examination of enucleated retinoblastoma eyes, it is observed by various authors that choroidal invasion by tumour cells, trans-scleral migration and optic nerve invasion by retinoblastoma cells are the most important predictors of metastatic retinoblastoma. 5

In our series, nine patients (23\%) were found to have HP Risk factors on re-examination. Though the significance of choroidal invasion of retinoblastoma with regard to its metastatic risk is controversial, a large study done by Shields et al showed that choroidal invasion, when present simultaneously with optic nerve invasion, it becomes a significant risk factor for metastasis. ${ }^{10}$ Optic nerve invasion beyond lamina cribrosa in Retinoblastoma is associated with greater metastatic risk. ${ }^{11}$ In our own series, 2 children whose HP report was incomplete came back with recurrence and 2 more children who had HP risk factors also had recurrence, hence, we prefer and advise antimetastatic chemotherapy to all these children.

A large study on 142 enucleated retinoblastoma eyes, done by R Gupta et al, shows presence of HP risk factors, in $54.2 \%$ of patients. Choroidal invasion being seen in maximum number of patients (40\%) followed by retrolaminar optic nerve involvement in (17\%) their series. ${ }^{12}$

Another study by S. Rao et al, reported choroidal invasion (58.8\%) and anterior chamber seeding (47.2\%) as the common HP risk factors for possible metastasis. ${ }^{13}$

In our series we found that, although 39 enucleated eyes had no involvement of "cut end of optic nerve by tumour cells", on re-examination, nine eyes $(23 \%)$ did show presence of HP risk factors. Choroidal invasion (6 cases $-15.3 \%$ ) and laminar Optic Nerve invasion ( 6 cases $-15.3 \%$ ) being the most common type of HP risk factors seen in our study group. Four of these nine children returned with features of orbital and systemic metastasis. This only emphasises the need for careful HP examination and subsequent antimetastatic treatment. When clinical records were reviewed, these nine eyes with HP risk factors also had clinical risk factors. The clinical risk factors should be mentioned in the request form to the pathologist. The possible sites of choroidal invasion like vortex veins, muscle insertion, the site of largest tumour should be mentioned in the HP form. The specimen should be sectioned at the site of the largest tumour. The pathologist should be requested to mention the absence of HP risk factors that are being specifically asked for. Though the sample size of our study is small, the importance of HP risk factors cannot be ignored, as the course of adjuvant chemotherapy depends on this report. This can considerably reduce the risk of future recurrence and thereby improving the overall survival of such high-risk patients.

\section{CONCLUSION}

The purpose of this study was to emphasise the importance of various HP risk factors in Retinoblastoma among treating ophthalmologists, oncologists and pathologists. We would also like to stress the need for mentioning the clinical risk factors while sending the enucleated eye for HP examination and specifically request for examination of HP risk factors in suspected cases. An experienced pathologist should examine the HP specimen and slides, preferably with an Oncologist. Patients showing any HP risk factors should be treated with antimetastatic chemotherapy. This will definitely increase the chances of tumour-free survival of retinoblastoma patients.

\section{REFERENCES}

[1] Shields JA, Shields CL. Management and prognosis of retinoblastoma. In: Intraocular tumors: a text and Atlas. Philadelphia, WB Saunders, 1992:377-92.

[2] Ellsworth RM. The practical management of retinoblastoma. Trans Am Ophthalmol Soc 1969;67:462-534.

[3] Kopelman JE, McLean IW, Rosenberg SH. Multivariate analysis of risk factors for metastasis in retinoblastoma treated by enucleation. Ophthalmology 1987;94(4):371-7.

[4] Khelfaoui F, Validire P, Auperin A, et al. Histopathologic risk factors in retinoblastoma: a retrospective study of 172 patients treated in a single institution. Cancer 1996;77(6):1206-13.

[5] Finger PT, Harbour JW, Karcioglu ZA. Risk factors for metastasis in retinoblastoma. Surv Ophthalmol 2002;47(1):1-16.

[6] Honavar SG, Singh AD, Shields CL, et al. Postenucleation adjuvant therapy in high-risk retinoblastoma. Arch Ophthalmol 2002;120(7):92331.

[7] Ryan S, Schachat A, Wilkinson C, et al. Retina. Vol 1, 4th edn. Elsevier Mosby, 2006:pp 3104.

[8] Chantada GL, Dunkel IJ, de Dávila MT, et al. Retinoblastoma patients with high risk ocular pathological features: who needs adjuvant therapy? $\mathrm{Br}$ J Ophthalmol 2004;88(8):1069-73.

[9] Zimmerman LE. Retinoblastoma and retinocytoma. In: Spencer WH, (eds). Ophthalmic pathology: an Atlas and textbook. 3rd edn. Vol. 2. Philadelphia: WB Saunders, 1985:1292-351.

[10] Shields CL, Shields JA, Baez KA, et al. Choroidal invasion of retinoblastoma: metastatic potential and clinical risk factors. Br J Ophthalmol 1993;77(9):5448.

[11] Shields CL, Shields JA, Baez K, et al. Optic nerve invasion of retinoblastoma. Metastatic potential and clinical risk factors. Cancer 1994;73(3):692-8.

[12] Gupta R, Vemuganti GK, Reddy VA, et al. Histopathologic risk factors in retinoblastoma in India. Arch Pathol Lab Med 2009;133(8):1210-4.

[13] Rao S, Sobti P, Khurana N, et al. High-risk histomorphological features in retinoblastoma and their association with p53 expression: an Indian experience. Indian J Ophthalmol 2014;62(11):106971. 